\title{
Elastic parameters of poplar wood with end-cracks
}

\author{
Mehran RooHnia $^{1 *}$, Ali YAVARI ${ }^{2}$, Ajang TAJDINI $^{1}$ \\ ${ }^{1}$ Agriculture Research Center (KIAU-ARC) Islamic Azad University, Karaj Branch Moazen BLVD, Rajaee-shahr, P.O. Box 31485-313, Karaj, Iran \\ ${ }^{2}$ Department of Wood Science \& Technology, Islamic Azad University, Karaj Branch Moazen BLVD, Rajaee-shahr, P.O. Box 31485-313, Karaj, Iran
}

(Received 16 March 2009; accepted 5 September 2009)

Keywords:

crack /

damage /

elasticity /

free vibration /

Populus Deltoides

\author{
Mots-clés : \\ fissure / \\ endommagement / \\ élasticité / \\ vibration libre / \\ Populus deltoides
}

\begin{abstract}
- In this study, longitudinal specific modulus of elasticity along the grain ( $\operatorname{specific} \mathrm{MOE}_{L}=\mathrm{MOE}_{L} / \rho$ ) as well as radial and tangential shear moduli $\left(G_{L R}\right.$ and $\left.G_{L T}\right)$ of Populus Deltoides wood were examined in free flexural vibration in a free-free bar method, where end-cracks produced manually in $L T$ plane along and parallel to annual rings in four different sizes.

- The effects of four different crack sizes $(0,6,12$, and $18 \mathrm{~cm})$ on elastic parameters of the bars were examined for their vibration properties based on Timoshenko bar equations, in order to find a procedure to make a confident choice of a clear specimen among the cracked ones, considering three initial modes of vibration.

- Based on research findings, a significant correlation existed between radial and tangential shear moduli of the clear bars as $G_{L R}$ was approximately 15 percents higher than $G_{L T}$. After making the shortest crack sizes, however, this correlation entirely faded. Statistically for $6 \mathrm{~cm}$ crack, decreases in specific $\mathrm{MOE}_{L}$ for measurement on the tangential impact were not significant though they were for longer cracks.

- It was also revealed that in specimen under the study if longitudinal specific modulus of elasticity from both $L R$ and $L T$ flexural vibrations were almost equal and $G_{L R}$ was slightly larger than $G_{L T}$, the user could be confident enough to consider the specimen without severe longitudinal cracks.
\end{abstract}

Résumé - Les constantes élastiques du bois de peuplier fissuré aux extrémités.

- Dans cette étude, le module d'élasticité longitudinal spécifique (MOEL/ $\rho$ ) et les modules de cisaillement radial et tangentiel $\left(G_{L R}\right.$ and $\left.G_{L T}\right)$ du bois de Populus deltoides ont été mesuré en vibration de flexion libre-libre pour quatre différentes longueurs de fissures initiées manuellement dans le plan $L T$ qui est parallèle au fil du bois et tangentiel aux limites de cernes.

- Les effets des quatre différentes tailles de fissures $(0,6,12$ et $18 \mathrm{~cm})$ sur les constantes élastiques des barres ont été examinées pour leurs propriétés vibratoires sur la base des équations de Timoshenko, dans le but de trouver une procédure conduisant à un choix fiable d'un échantillon sans défauts parmi les échantillons fissurés, ceci en considérant les trois modes initiaux de vibration.

- Les résultats obtenus montrent une corrélation significative entre les modules de cisaillement radial et tangentiel des barres sans défauts, $G_{L R}$ étant environ 15 pour cent plus élevé que $G_{L T}$. Cependant après avoir réalisé les fissures les plus courtes cette corrélation n'existe plus. Pour une fissure de $6 \mathrm{~cm}$, la décroissance du module longitudinal spécifique mesuré en tangentiel n'est pas significative alors que c'était le cas pour des fissures plus longues.

- Pour nos échantillons, nous avons également montré que si les modules d'élasticité longitudinaux spécifiques sont presque identiques et $G_{L R}$ légèrement plus important que $G_{L T}$, l'utilisateur peut exploiter en confiance les échantillons sans fissures importantes.

\section{INTRODUCTION}

After knots, cracks are the most important defects in wood and wood composites which cause limitations in their performance. Consequently, the effects of cracks on wood performance have been the prime interest in most mechanical testing. In addition to standard tests, non-destructive methods

*Corresponding author: mehran.roohnia@kiau.ac.ir have recently been used to evaluate the mechanical parameters and their behaviors.

In this field, vibration-based techniques are widely known as fast, reliable, and inexpensive procedures for crack identification (Loutridis et al., 2005). Since a crack affects the dynamic behavior of a bar by reducing the natural frequencies and the probable mechanical derivatives, examining these changes makes it possible to understand the effects of cracks size and position on mechanical properties. 
Recently, the effects of cracks shape, position and behavior during the vibration have widely been investigated. Similarly, the instantaneous frequency and empirical mode of decomposition for crack detection in cantilever beams with breathing cracks have been studied (Loutridis et al., 2005). In another research, the free and forced vibrations for crack detection in cantilever beams were examined and it was proved whereas free vibration analysis could provide valuable information to single and multiple cracks detection, forced vibration could only detect the single cracks (Orhan, 2007). However, it was argued that dynamic response in forced vibration could better describe the changes in crack depth and location comparing to free vibration in which the differences between natural frequencies corresponding to a change in crack depth and location only indicated minor effects. Along the same line, the vibrations caused by two impact shocks and the signals in both defect-free and cracked bars were analyzed and compared in a frequency domain (Cam et al., 2005). The research findings offered a procedure for determining the depth and location of cracks by analyzing the vibration signals. Moreover, the experimental results out of dynamic behavior of a circular arch in several undamaged and damaged configurations have been reported and they were compared with those obtained by means of analytical methods; acceptable agreement was observed between the analytical and experimental results and an identification procedure based on frequency measurements was proposed and validated (Cerri et al., 2008). Modal-based damage detection algorithm for identifying the location and extent of the defects in timbers was the subject of a recent study that came up with some modifications to the existing defect detection algorithms. In this study, researchers used the two initial modes of vibration to compare the modal strain energy before and after damage (Choi et al., 2007). In order to compare the mode shapes of vibration before and after damage in timbers, modal-based testing was applied on wood bars in order to propose a new statistical algorithm for obtaining a defect indicator (Hu et al., 2006). Last but not least, free vibration testing was used to generate the two initial mode shapes for damage detection in timbers and it was proved that the chosen Daubechies 3 wavelet was suitable and sufficiently sensitive to identify the location, extent and number of different damages ( $\mathrm{Hu}$ et al., 2006).

As far as research in the field is concerned, longitudinal cracks have seldom been noticed. To examine other types of imperfections, the evaluation of longitudinal cracks in wood bars in terms of modulus of elasticity and the shear modulus was foreseen in the current study. Experiments on theoretical predictions were carried out in order to testify the significant effects of the longitudinal cracks on decreasing the modulus of elasticity and the shear modulus in poplar wood or presence of any positive relationship between them.

\section{MATERIALS AND METHODS}

The specific longitudinal modulus of elasticity $\left(\mathrm{MOE}_{L} / \rho\right)$ and the shear modulus can be evaluated based on Timoshenko bar equations and Bordonné Solution (Bordonné, 1989; Brancheriau et al., 2002). In this equation, after obtaining the $k$ th frequency through Fourier
Transform, considering $a_{k}$ and $b_{k}$, the value of longitudinal specific modulus of elasticity was determined using a linear regression formula as following:

$$
\begin{gathered}
a_{k}=\left(\frac{\mathrm{MOE}}{\rho}\right)-\left(\frac{\mathrm{MOE}}{K \times G_{i j}}\right) b_{k} \\
b_{k}=\frac{4 \pi^{2} l^{2} f_{k}^{2} F_{2 k}}{X_{k}} \\
a_{k}=\frac{\left[4 \pi^{2} l^{2} f_{k}^{2}\left(1+\alpha F_{1 k}\right)\right]}{\alpha X_{k}} \\
X_{k}=m_{k}^{4} \\
\alpha=\frac{I}{A l^{2}}
\end{gathered}
$$

where $I$; moment of inertia, $A$; cross section area, $l$; length of the specimen, $K$; shape coefficient (the value of $5 / 6$ can be used for a rectangular cross section), $G_{i j}$; shear modulus in plane of vibration $\left(G_{L T}\right.$ or $\left.G_{L R}\right), \rho$; specific gravity, $f_{k}$; frequency of the $k$ th mode of vibration obtained from FFT spectrum $m_{k}$; the $k$ th results in following equation:

$$
m_{k}=\frac{(2 k+1) \pi}{2} .
$$

In Equations (1) and (2), $F_{1 k}$ and $F_{2 k}$ can be calculated as following:

$$
\begin{gathered}
F_{1 k}=\Theta^{2}\left(m_{k}\right)+6 \Theta\left(m_{k}\right) \\
F_{2 k}=\Theta^{2}\left(m_{k}\right)-2 \Theta\left(m_{k}\right) \\
\Theta_{\left(m_{k}\right)}=\frac{\left[m_{k} \tan \left(m_{k}\right) \tanh \left(m_{k}\right)\right]}{\left[\tan \left(m_{k}\right)-\tanh \left(m_{k}\right)\right]} .
\end{gathered}
$$

Higher correlation coefficients of the estimated trend lines in Equation (1) benefit the specimens with more homogeneity, where the Timoshenko model has been fitted initially to isotropic materials, and next to the clearest specimens. The selection was made based on trends with correlation coefficients higher than 0.99 .

In this study, Eastern poplar (Populus Deltoides) timbers were randomly collected from plantations in Zanjan province in the region between West Alborz and North Zagros Mountains. Eastern poplar wood is a common commercial wood with widespread use in Iran. Following ISO 3129 international standard (1975), 25 rectangular and visually clear wooden bars (specimens) were obtained. The specimens were cut to their final nominal dimensions of $2 \times 2 \times 36 \mathrm{~cm}$, $R \times T \times L$, and kept in a conditioning chamber at $21^{\circ} \mathrm{C}$ and 65 percents relative humidity for two weeks until their moisture content was stabilized. In controlled pathways, the $0,6,12$ and $18 \mathrm{~cm}$ cracks parallel to annual rings were produced with a carpentry chisel in longitudinal directions. The cracks were visible on opposite radial surfaces (Fig. 1).

Free flexural vibration on free-free bars, rested on soft thin rubber, was performed for all crack sizes. Individual impacts on either radial or tangential surface excited the bar to vibrate in $L T$ and $L R$ planes respectively (Fig. 2). The impacts were applied on the whole end where the microphone was located on the cracked end over the center of both crack legs. Vibrations were recorded as audio files at sampling rate of $44100 \mathrm{~Hz}$. Every selected and saved acquisition sound file contained 14000 to 18000 points, depending on the attenuation through the time that was less than a second. After reading the audio files at the 

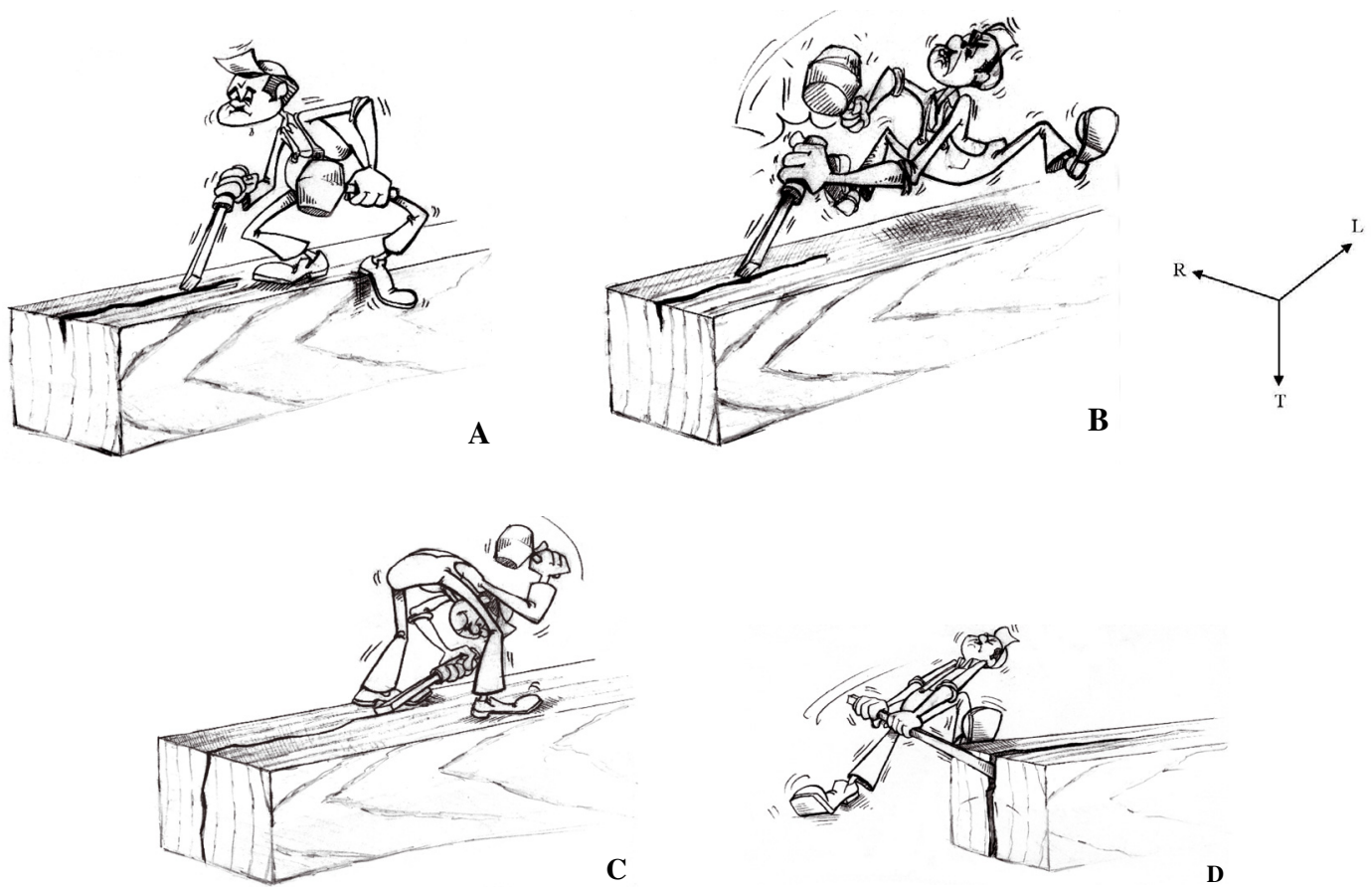

Figure 1. Cracks in plane with $L T$ surface of a $2 \times 2 \times 36 \mathrm{~cm} R \times T \times L$ bar. Crack production, controlled in a proper pathway. Look to procedure A to D.
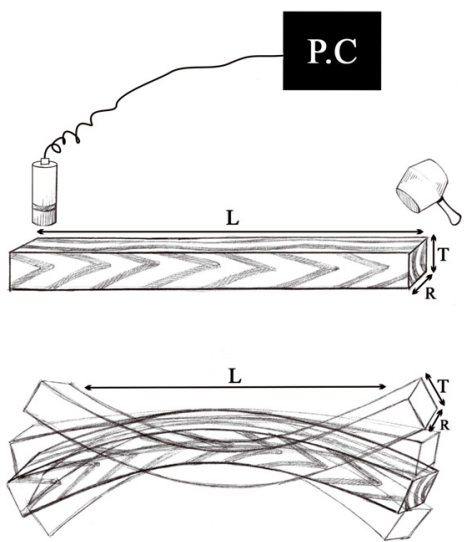

Figure 2. Schematic view of the most common setups for free flexural vibration on a free-free bar test. Sound recording from cracked end and hammer impact on other free end of a bar leaned on two soft thin supports, $0.22 L$ from each end.

same sampling rates, the three initial modes of vibration were obtained from magnitude of Fourier Transform spectrum in MATLAB v.7.1 (Fig. 3).

To analyze the obtained data, some statistical tests were conducted in SPSS 11.5. Using one-way analysis of variances (ANOVA) followed by Duncan multiple comparison tests, the effects of step-wise crack propagation on elastic parameters were analyzed and the presence of significant correlations in clear bars before damage was studied during and after the crack production from one free end into the middle of the bars.

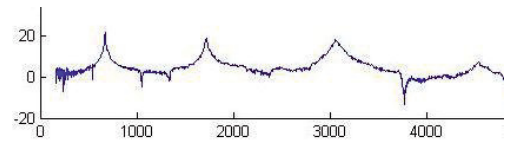

Figure 3. Three initial modes of vibration-magnitude of a Fourier Transform. $Y$ axis corresponding to amplitude in $d B$ and $X$ axis the frequency in $\mathrm{Hz}$.

\section{RESULTS AND DISCUSSION}

Prior to presenting the research findings, a discussion on the definition of elastic modulus seems necessary. Elastic modulus is usually defined as a material property but in this study it is specifically defined as the response of a bar. In the former case, the property itself does not change after geometrical manipulations of the bar, although the response of the bar would be affected. However, when the bar is under impact on its transverse surface, the vibration is excited in $L R$ plane. The bar legs frequently hit each other so that it eventually results in fading the resonance frequency. Therefore, decreasing the natural frequencies would decrease the elastic parameters due to their positive correlations with the resonance frequencies in Timoshenko bar equations.

In the current study, since only one longitudinal specific modulus of elasticity was adopted for a normal grain wood, there would be almost equal estimates out of vibrations in $L T$ or $L R$ planes before the presence of any defects. However in some cases, small differences could be observed since probably some differences existed in MOE between the early and late woods. This would lead to a higher MOE out of vibration 

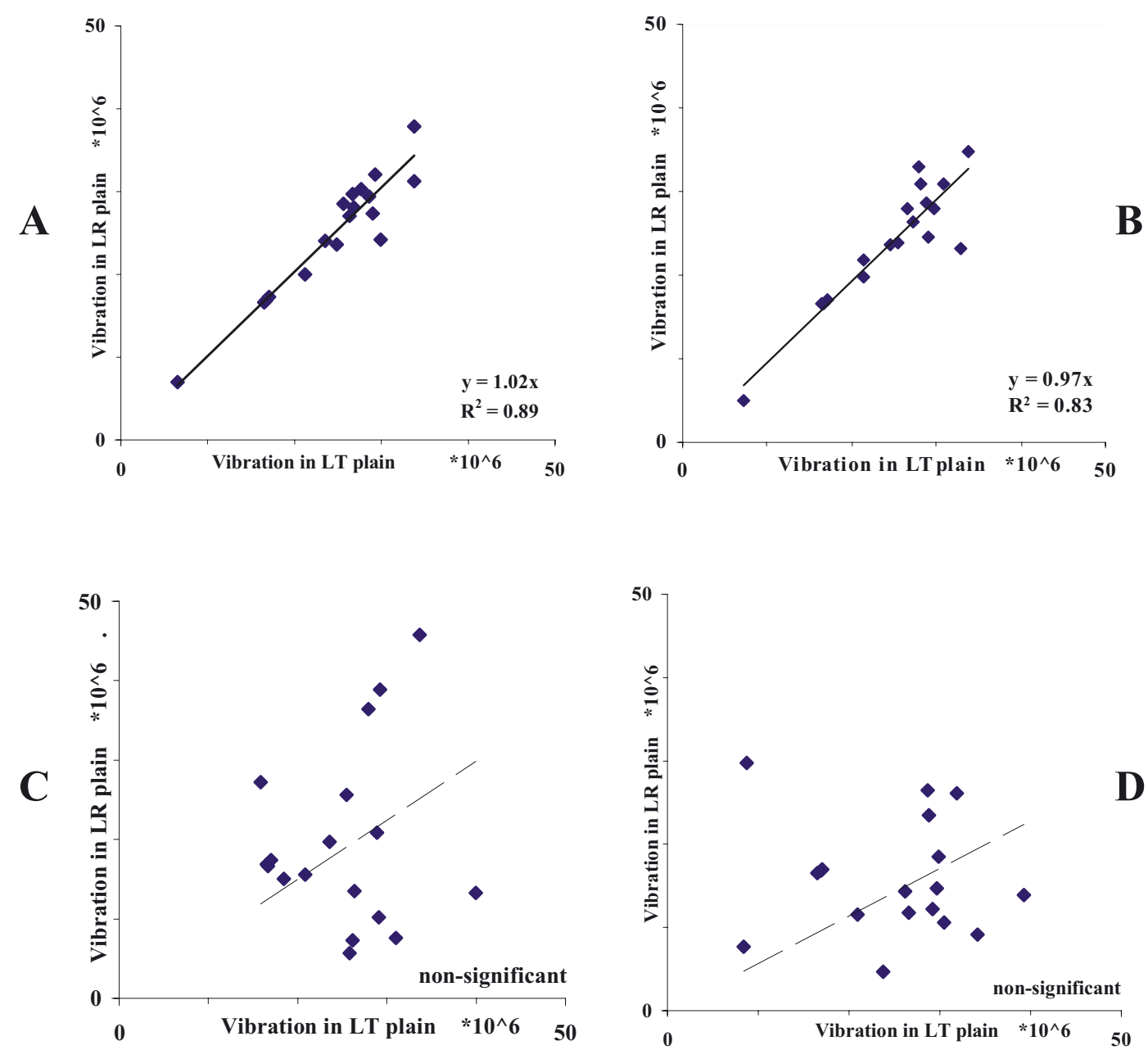

Figure 4. Comparison of longitudinal specific modulus of elasticity ( $\left.\mathrm{MPa} / \mathrm{Kg} / \mathrm{m}^{3}\right)$, results of vibrations in $L R$ and $L T$ planes of clear bars (A) statistically, the constant in linear equation was not significant; of $6 \mathrm{~cm}$ cracked bars (B); of $12 \mathrm{~cm}$ cracked bars (C); of $18 \mathrm{~cm}$ cracked bars (D). Based on 18 observations.

in $L R$ plane rather than vibration in $L T$ plane. Apart from these small and dispensable differences, after producing cracks at least one of the vibrations would result in smaller natural frequencies; hence smaller values of the longitudinal specific modulus of elasticity (Loutridis et al., 2005). It is worth mentioning that non-destructive vibration method is suitable in case of isotropic materials or in orthotropic directions. A defect which could fade homogeneities would result in weakening the present correlations.

In the next step, longitudinal specific modulus of elasticity as well as two shear moduli of 25 samples for individual crack sizes was measured. Based on Timoshenko bar equation, closely considering correlation coefficients higher than $0.99,18$ out of 25 measurements were accepted as the clearest ones and taken into account for further analyses. The effects of different crack sizes on each elastic parameter were examined using one-way analysis of variances (ANOVA) followed by Duncan multiple comparison tests (Supplementary Tables S1S3 available at www.afs-journal.org). Even though cracks occasionally caused the vibration test unsuccessful in elastic pa- rameters evaluation (mostly due to low correlation coefficients in linear regression equations and some unexpected negative values) when the specimen was vibrated in $L T$ plane (parallel to crack plane) it was possible to predict the crack sizes had no significant effects on elastic parameters. This could be due to the free vibration of each crack leg so that the homogeneity barely changed in $L T$ plane. Theoretically, the elastic parameters were not expected to be affected by cross-sectional dimensions.

Statistical analysis showed that smaller cracks (e.g., $6 \mathrm{~cm}$ or even $12 \mathrm{~cm}$ cracks) did not significantly decrease the specific modulus of elasticity (Sup. Table S2). Meanwhile, the Pearson product moment correlations between the longitudinal specific modulus and the results of vibrations in $L R$ against $L T$ plane proved the stable equality of the two obtained series even at the $6 \mathrm{~cm}$ cracked bars.

In larger crack sizes, the correlation completely lost its significance (Fig. 4). The results, therefore, indicated that changes in specific modulus of elasticity cannot be relied on for identifying the smaller cracks. 

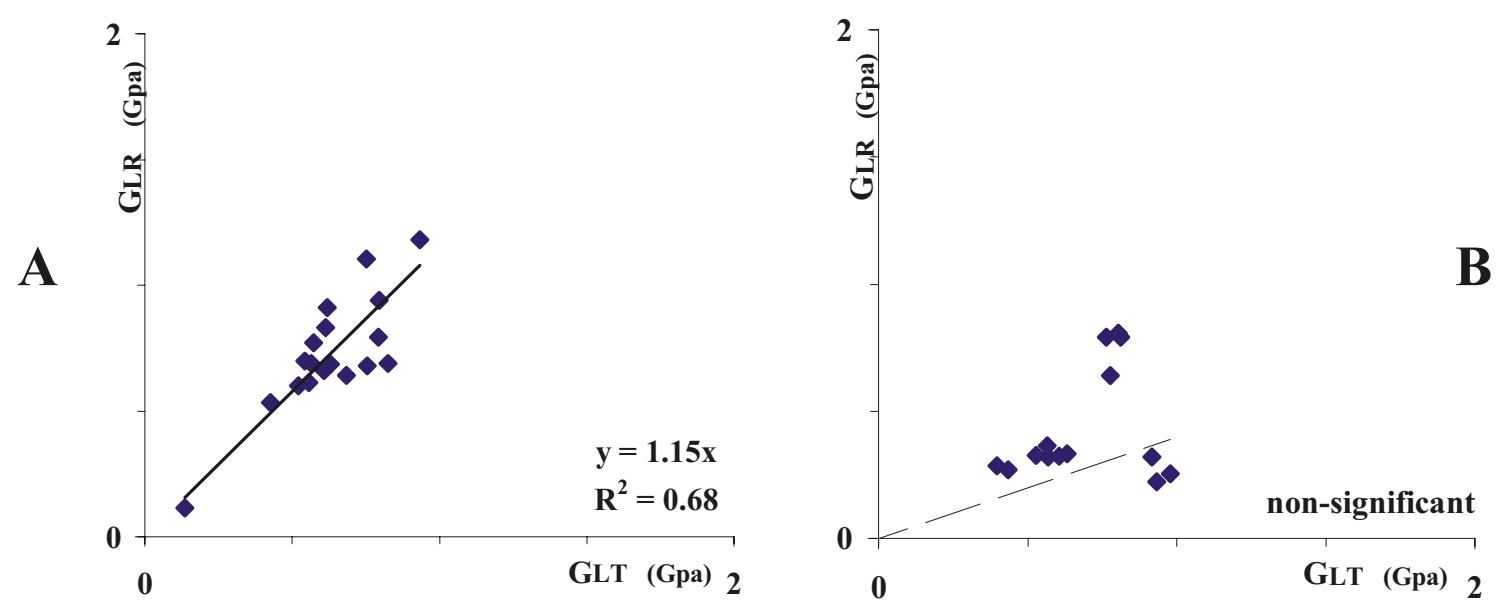

Figure 5. Comparison of shear moduli, $G_{L R}$ and $G_{L T}$, in clear bars, the non-significant constant in linear equation (A); in $6 \mathrm{~cm}$ cracked bars (B). Based on 18 observations.
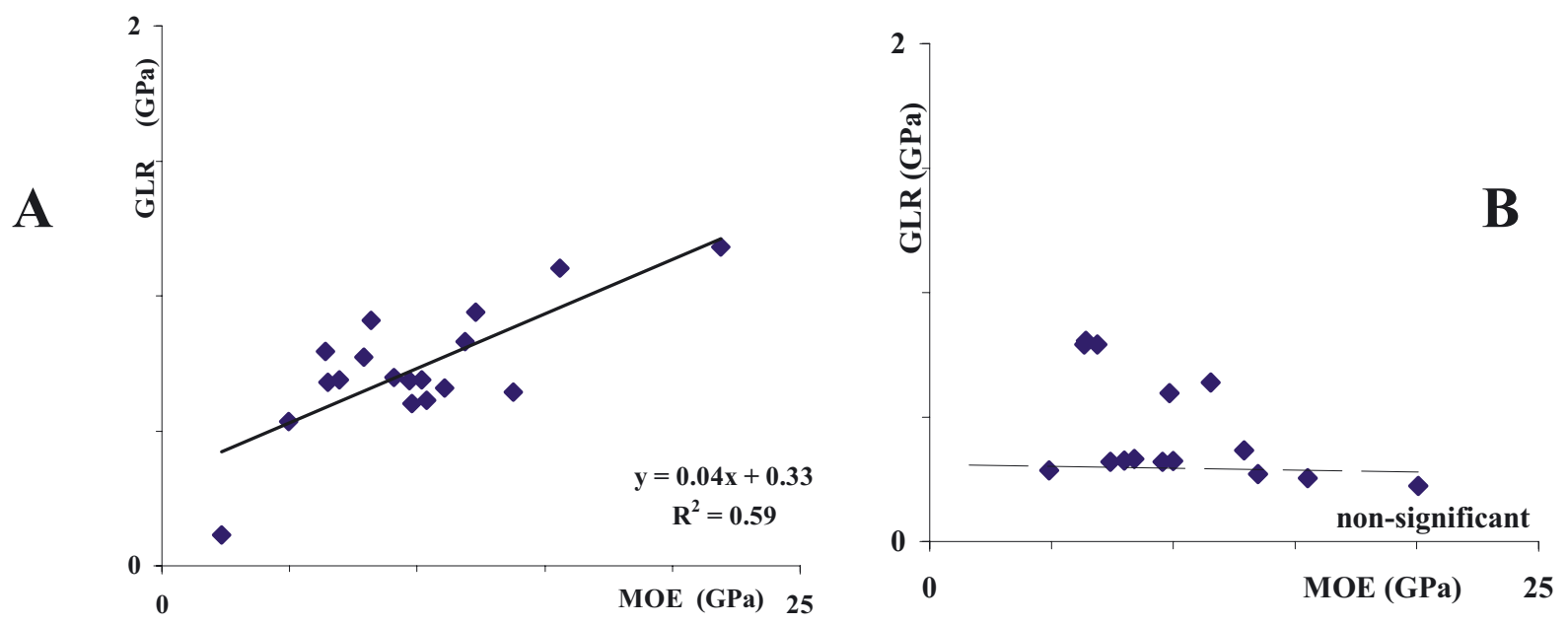

Figure 6. Correlations between radial shear modulus $\left(G_{L R}\right)$ and longitudinal modulus of elasticity $\left(\mathrm{MOE}_{L}\right)$. Results of vibration in $L R$ plane in clear bars (A). Significant constant in linear equation, in $6 \mathrm{~cm}$ cracked bars (B). Based on 18 observations.

In the first step of crack production, a decrease in $G_{L R}$ was initially observed (Tab. S3). In Figure 5, the correlation coefficients for two series of shear moduli are shown where $G_{L R}$ was approximately 15 percents higher than $G_{L T}$ in the non-cracked clear bars. As the length of the crack increased, however, this correlation was entirely lost (Fig. 5). The results also showed that in a proper direction, the numerical finger prints of initial longitudinal cracks on shear modulus might be applicable in crack identification, because even in non-cracked clear specimens there was not a significant correlation between $\mathrm{G}_{L T}$ and the longitudinal modulus of elasticity $\left(\mathrm{MOE}_{L}\right)$. Opposite to $\mathrm{G}_{L T}, \mathrm{G}_{L R}$ showed highly significant correlation. Upon starting the first step of $L T$ crack production, however, the described correlation for $\mathrm{G}_{L R}$ entirely faded (Fig. 6).

This study, therefore, has introduced a new approach to the phenomenon that would happen if the vibration was excited in the cracked end and measured in the whole end of the bar. This new approach, however, was discovered right after the ending point of crack production when the smaller cracks were not available anymore. The authors barely noticed any important differences between two opposite ends for the microphone and excitation place but to them it seems critical to re-examine the research findings in early future.

\section{CONCLUSION}

This study was carried out to investigate the accuracy of predictions for the positive effects of crack length on elastic moduli of poplar wood when the vibration was perpendicular to the crack surface. This assumption was experimentally proved to be true, though the desirable effects were exclusively traced in longer cracks. The research findings indicated that 
the changes in the modulus of elasticity and its specific values were not statistically reliable finger prints for identifying the smaller cracks in the poplar wood.

As it was expected, the initial crack size in this study affected the shear modulus in perpendicular direction to the crack plane (i.e., $L T$ crack and $\mathrm{G}_{L R}$ ). Therefore it can be concluded that finger prints of initial longitudinal cracks on shear modulus in proper directions might be applicable for crack identification. In case the longitudinal modulus of elasticity obtained in both vibrations in $L T$ and $L R$ planes would not be nominally equal to one another, only in individual specimen of poplar wood under study, there would be enough reasons for defects (i.e., crack) existence.

Finally, if both of the above-mentioned longitudinal moduli of elasticity were nominally equal to one another and the $G_{L R}$ was nominally slightly larger than the $G_{L T}$, the user could be confident enough that his specimen is without severe longitudinal cracks.

Acknowledgements: Our special thanks go to Dr. Iris Bremaud and Dr. Loic Brancheriau, expert scientists from Montpellier, France, for their kind and valuable comments during the course of experiments, Dr. Ahmad Jahan-latibari and Dr. Natasha Qale from Islamic Azad University, Karaj Branch for their assistance with the English revisions, and finally we sincerely thank Mr. Rahi Gaffarian from Islamic Azad University, Karaj Branch and Ms. Negin Manouchehri from University of Tehran for their caricatures and drawings.

\section{REFERENCES}

Bordonné P.A., 1989. Module dynamique et frottement intérieur dans le bois: Mesures sur poutres flottantes en vibrations naturelles. Ph.D. thesis, INP Lorraine, Nancy, $154 \mathrm{p}$.

Brancheriau L. and Bailleres H., 2002. Natural vibration analysis of clear wooden beams: a theoretical review, Springer-Verlag. Wood Sci. Technol. 36: 347-365.

Cam E., Orhan S., and Luy M., 2005. An analysis of cracked beam structure using impact echo method. NDT E Int. 38: 368-373.

Cerri M., Dilena N., and Ruta G.C., 2008. Vibration and damage detection in undamaged and cracked circular arches: experimental and analytical results. J. Sound Vibr. 314: 83-94.

Choi F.C., Li J., Samali B., and Crews K., 2007. Application of modalbased damage-detection method to locate and evaluate damage in timber beams. J. Wood Sci. 53: 394-400.

Hu C. and Afzal M.T., 2006. A statistical algorithm for comparing mode shapes of vibration testing before and after damage in timbers. J. Wood Sci. 52: 348-352.

Hu C. and Afzal M.T., 2006. A wavelet analysis-based approach for damage localization in wood beams. J. Wood Sci. 52: 456-460.

Loutridis S., Douka E., and Hadjileontiadis L.J., 2005. Forced vibration behaviour and crack detection of cracked beams using instantaneous frequency. NDT E Int. 38: 411-419.

Orhan S., 2007. Analysis of free and forced vibration of a cracked cantilever beam. NDT E Int. 40: 443-450.

Wood - Sampling Methods and General Requirements for Physical and Mechanical Tests - 1975 - 11 - 01 - International Standard ISO 3129. 